\title{
The Role Of Long Distance Migration In The Rural Renaissance, In Gentrification, And In Growth Of The Sunbelt $\dagger$
}

\author{
William J. Serow*
}

\section{INTRODUCTION}

During the 1970 s, a considerable amount of research has been undertaken on population growth and migration patterns for metropolitan versus nonmetropolitan areas because of the possibility of a widespread return of persons to central cities due to changing lifestyles or increased energy costs, and on the continuing flows of individuals from the Northeast and North Central regions of the nation to the South and West. The aim of thispaper is to decompose national trends in two ways: first, by distance moved in the migration process and, second, by region of origin and of destination. Thus, we seek to find out whether any apparent nationwide trend is the result of short versus long distance moves and whether these nationwide trends are, in fact, trends evident only in one or two portions of the country.

The data utilized in this paper are from the March 1975 and March 1979 Current Population Surveys, which asked the place of residence of all persons five (four) years of age and over in 1970 or in 1975, respectively. Thus, two sets of migration data are used: that for the 1970-1975 period [U.S. Bureau of the Census, 1975] and that for the 1975-1979 period [U.S. Bureau of the Census, 1980b].

While the migration question asked of respondents in each survey was essentially identical, one must exercise some care in comparing results for the two periods. As noted, the population at risk for the 1979 Survey is slightly more comprehensive (including persons aged four and over) than the 1975 Survey, although the migration behavior of four year old children is not likely to exercise much effect on overall migration patterns. More importantly, the shorter time span covered by the 1979 Survey will lead to the illusion that there was somewhat more mobility from 1975 to 1979 than there was from 1970 to 1975, at least on an average annual basis. As the interval of the migration period lengthens, the number of persons who moved during the period is transformed from being an approximation of the number of moves during the period to being an approximation

†Prepared for presentation at the annual meeting of the Southern Regional Science Association, Rosslyn, Virginia, April 14-16, 1981.

*Professor of Economics and Research Associate, Center for the Study of Population, Florida State University. 
of the proportion of the population affected by mobility [U.S. Bureau of the Census, 1980 b, p. 3$]$. For survey purposes, a person can be counted as having moved only once during the interval; comparison is made of the place of residence at the beginning and at the end of the interval. Thus, repeat or return moves during the interval are lost or cancelled out. The greater the length of the interval, the greater the probability of such a return or repeat move. Finally, during the passage of time between the 1975 and 1979 Surveys, the number of areas covered in the Survey was expanded from 461 to 614.

Despite these shortcomings, it is instructive to compare broad trends in migration to/from central cities, suburbs, and nonmetropolitan areas by race and region for 1970-1975 and 1975-1979. The focus here will be largely on interstate moves, due in part to the lack of detailed origin/ destination data for 1970-1975 and in part to the fact that many intrastate moves are between the member localities of a given metropolitan area or are from a metropolitan to a proximate nonmetropolitan area. Interstate moves will be divided into interregional (which will be taken as a proxy for long distance mobility) and intraregional, but interstate (medium distance mobility), moves. Throughout the discussion, the basic unit of measurement will be the average annual number of persons represented by a particular flow(s).

One should also recognize that lack of age detail for migration flows by region and type of residence preclude commentary on the causal dimensions of these flows. In particular, migration of the elderly is particularly different from that of the rest of the population, in terms of both spatial aspects (Flynn, 1980; Rives and Serow, 1981) and migration behavior determinants (Cebula, 1974; Long and Hansen, 1979).

\section{METROPOLITAN VERSUS NONMETROPOLITAN GROWTH}

A strong flow from rural or nonmetropolitan areas to urban or metropolitan areas has long been characteristic of migration behavior in the United States. During the 1970s, this trend seems to be unmistakably reversed, as suggested by analysis of current estimates of population [Beale, 1975] and of the mid-decade Current Population Survey [Tucker, 1976]. This phenomenon seems to be reflecting individuals' preferences of desired place of residence [Fuguitt and Zuiches, 1975] and is now being realized through increased employment opportunities in nonmetropolitan areas [Bowles, 1978; Wardwell and Gilchrist, 1980].

Table 1 shows the average annual interstate flow to and from the nonmetropolitan portions of each of the four regions of the nation from 1970 to 1975 and from 1975 to $1979 .{ }^{1}$ For the reasons cited previously, the annual averages are generally larger in the later of these periods. The net flow, however, was larger from 1975 to 1979, although the overall difference of 25 thousand per year is not large enough to indicate any definite trend regarding relative nonmetropolitan growth through interstate migration. 
Overall, the trend towards nonmetropolitan net inmigration is largely a phenomenon of the Southern région, at least as far as interstate migration is concerned. Only in the South is the average annual flow consistently greater than zero and only in the South is the flow to nonmetropolitan areas largely the consequence of interregional migration. A similar pattern is found in the West throughout the decade, but with much less magnitude. Intraregional migration, as well as intrastate (at least for 19751979) migration, shows a persistent net flow to nonmetropolitan areas in all regions throughout the decade. ${ }^{2}$

TABLE 1.

Average Annual Flow to/from Nonmetropolitan Areas, by Region and Race: 1970-1979

(thousands of persons)

\begin{tabular}{|c|c|c|c|c|c|c|}
\hline \multirow{2}{*}{$\begin{array}{l}\text { Region and } \\
\text { Race }\end{array}$} & \multicolumn{3}{|c|}{$1970-1975$} & \multicolumn{3}{|c|}{$1975-1979$} \\
\hline & IN & OUT & NET & IN & OUT & NET \\
\hline \multicolumn{7}{|l|}{ Northeast } \\
\hline Interregional & 48 & 95 & -47 & 79 & 134 & -55 \\
\hline Black & 2 & 1 & 1 & 4 & 5 & -1 \\
\hline Intraregional & 79 & 55 & 24 & 95 & 78 & 17 \\
\hline Black & 0 & 1 & -1 & 2 & 1 & 1 \\
\hline \multicolumn{7}{|l|}{ North Central } \\
\hline Interregional & 101 & 170 & -69 & 158 & 184 & -26 \\
\hline Black & 0 & 6 & -6 & 4 & 4 & 0 \\
\hline Intraregional & 139 & 98 & 41 & 155 & 124 & 31 \\
\hline Black & 3 & 1 & 2 & 2 & 1 & 1 \\
\hline \multicolumn{7}{|l|}{ South } \\
\hline Interregional & 313 & 168 & 145 & 336 & 210 & 126 \\
\hline Black & 28 & 33 & -5 & 20 & 36 & -16 \\
\hline Intraregional & 232 & 222 & 11 & 294 & 257 & 37 \\
\hline Black & 22 & 32 & -10 & 23 & 23 & 0 \\
\hline \multicolumn{7}{|l|}{ West } \\
\hline Interregional & 108 & 73 & 35 & 125 & 98 & 27 \\
\hline Black & 1 & 1 & 0 & 3 & 3 & 0 \\
\hline Intraregional & 133 & 112 & 21 & 160 & 140 & 20 \\
\hline Black & 0 & 3 & -3 & 2 & 1 & 1 \\
\hline \multicolumn{7}{|l|}{ Total } \\
\hline Interregional & 570 & 512 & 58 & 698 & 626 & 72 \\
\hline Black & 31 & 41 & -10 & 31 & 48 & -17 \\
\hline Intraregional & 583 & 487 & 96 & 704 & 599 & 105 \\
\hline Black & 25 & 37 & -11 & 29 & 26 & 3 \\
\hline
\end{tabular}

Source: U.S. Bureau of the Census $[1975 ; 1980 \mathrm{~b}]$. 


\section{THE RETURN TO THE CITY?}

Along with the "rural renaissance," the 1970s have also seen considerable amount of attention being paid to the possibility of a widespread return to the city movement, especially among relatively affluent whites. Interestingly enough, ". . . there has been no formal endorsement of a back-to-the-city trend in data or publication of federal statistical agencies ..." [Long, 1980, pp. 63-64], and from a nationwide perspective not only is there little evidence of a return movement, but there has actually been an increase in the rate at which individuals leave central cities and a decrease in the rate at which they move to central cities during the decade [Goodman, 1980, pp. 14-15]. While there are definite increases in black to white housing successions in the nation's cities [Long and Spain, 1978; Spain, Reid, and Long, 1980], suggesting (along with differences in characteristics of in- and out-movers) some real degree of "gentrification," the phenomenon thus far appears to be one of selected neighborhoods rather than entire cities. Certainly, the evidence accumulated to data does not permit one to conclude there has been enough gentrification to affect economic differences between cities and suburbs [Long and Dahmann, $1980]$.

Tables 2 and 3 show average annual flows, by region of residence and race, for the nation's central cities and suburbs, respectively. Again, as expected for statistical reasons, flows in both directions are generally greater for 1975-1979 than for 1970-1975. However, net interstate flows from cities and to suburbs were lower (by about 40 thousand in each case) during the later period. The data suggest but, due to sampling limitations, do not conclusively show the beginning of net movement of blacks out of central cities and into suburbs [Farley, 1970; Nelson, 1978; Frey, 1978].

The decline in net interstate migration from central cities is attributable to greater increases in immigration to cities than outmigration from cities. This is a wholly nonblack movement and stems primarily from apparently substantial net interregional migration to central cities in the South and West. Conversely, for medium distance or intraregional (but still interstate) moves, net migration from cities showed little change from $1970-1975$ to $1975-1979$, regardless of region and race. ${ }^{3}$

The decline in net interstate migration to suburbs is caused by a combination of factors different from those described in the previous paragraph: a sharp decline in net interregional migration to suburbs with little change in net intraregional movement. Here too, migration behavior of blacks differs from that of the remainder of the population. Among blacks there is an increasing tendency toward movement to suburbs, particularly in the South and West.

Thus, to say that the data show evidence of a return to the city movement would be a gross overstatement. The data do reflect considerable net long distance migration of nonblacks to central cities in the West throughout the decade, especially during the later portion. During the first five years of the decade, long distance moves resulted in a net loss of about 200 thousand persons per year in central cities and increases of 140 and 60 
TABLE 2.

Average Annual Flow to/from Central Cities,

by Region and Race: 1970-1979

(thousands of persons)

\begin{tabular}{|c|c|c|c|c|c|c|}
\hline \multirow{2}{*}{$\begin{array}{l}\text { Region and } \\
\text { Race }\end{array}$} & \multicolumn{3}{|c|}{$1970-1975$} & \multicolumn{3}{|c|}{$1975-1979$} \\
\hline & IN & OUT & NET & IN & OUT & NET \\
\hline \multicolumn{7}{|l|}{ Northeast } \\
\hline Interregional & 50 & 162 & -112 & 54 & 182 & -128 \\
\hline Black & 17 & 29 & -12 & 16 & 42 & -26 \\
\hline Intraregional & 40 & 82 & -41 & 60 & 92 & -32 \\
\hline Black & 7 & 7 & 1 & 13 & 14 & -1 \\
\hline \multicolumn{7}{|l|}{ North Central } \\
\hline Interregional & 100 & 221 & -121 & 131 & 248 & -117 \\
\hline Black & 26 & 27 & -1 & 38 & 37 & 1 \\
\hline Intraregional & 71 & 115 & -44 & 67 & 105 & -38 \\
\hline Black & 10 & 14 & -4 & 12 & 12 & 0 \\
\hline \multicolumn{7}{|l|}{ South } \\
\hline Interregional & 178 & 179 & -1 & 212 & 232 & -20 \\
\hline Black & 21 & 18 & 3 & 28 & 33 & -5 \\
\hline Intraregional & 146 & 226 & -80 & 185 & 281 & -96 \\
\hline Black & 35 & 34 & 1 & 40 & 37 & 3 \\
\hline \multicolumn{7}{|l|}{ West } \\
\hline Interregional & 147 & 116 & 31 & 219 & 120 & 99 \\
\hline Black & 21 & 6 & 15 & 26 & 12 & 14 \\
\hline Intraregional & 84 & 109 & -25 & 127 & 155 & -28 \\
\hline Black & 5 & 3 & 2 & 5 & 8 & -3 \\
\hline \multicolumn{7}{|l|}{ Total } \\
\hline Interregional & 475 & 678 & -203 & 616 & 782 & -166 \\
\hline Black & 84 & 80 & 4 & 108 & 124 & -16 \\
\hline Intraregional & 341 & 532 & -191 & 439 & 633 & -194 \\
\hline Black & 57 & 58 & -1 & 69 & 71 & -2 \\
\hline
\end{tabular}

Source: U.S. Bureau of the Census $[1975 ; 1980 \mathrm{~b}]$.

thousand, respectively, in suburbs and nonmetropolitan areas. From 1975 to 1979 , these long distance moves resulted in an annual transfer, on balance, of about 165 thousand persons from cities and corresponding increases of 90 and 70 thousand persons in suburbs and nonmetropolitan areas, respectively. These changes are in contrast to short and medium distance moves which show more or less constant movement to suburbs and nonmetropolitan areas and more or less constant movement from cities.

\section{THE GROWTH OF THE SUNBELT}

During the 1970s, population growth in the United States, particularly that portion of it attributable to internal migration, has continued the 
TABLE 3.

Average Annual Flow to/from Suburbs, by Region and Race:

1970-1979

(thousands of persons)

\begin{tabular}{|c|c|c|c|c|c|c|}
\hline \multirow[b]{2}{*}{$\begin{array}{l}\text { Region and } \\
\text { Race }\end{array}$} & \multicolumn{3}{|c|}{$1970-1975$} & \multicolumn{3}{|c|}{ 1975-1979 } \\
\hline & IN & OUT & NET & IN & OUT & NET \\
\hline \multicolumn{7}{|l|}{ Northeast } \\
\hline Interregional & 113 & 223 & -110 & 127 & 220 & -93 \\
\hline Black & 5 & 6 & -1 & 6 & 10 & -4 \\
\hline Intraregional & 96 & 79 & 17 & 126 & 110 & 16 \\
\hline Black & 1 & 1 & 0 & 2 & 2 & 0 \\
\hline \multicolumn{7}{|l|}{ North Central } \\
\hline Interregional & 146 & 188 & -42 & 169 & 253 & -84 \\
\hline Black & 4 & 8 & -4 & 7 & 10 & -3 \\
\hline Intraregional & 113 & 110 & 2 & 136 & 129 & 7 \\
\hline Black & 2 & 0 & 2 & 5 & 7 & -2 \\
\hline \multicolumn{7}{|l|}{ South } \\
\hline Interregional & 326 & 104 & 222 & 349 & 186 & 163 \\
\hline Black & 12 & 7 & 5 & 30 & 7 & 23 \\
\hline Intraregional & 222 & 152 & 69 & 260 & 201 & 59 \\
\hline Black & 18 & 9 & 9 & 25 & 28 & -3 \\
\hline \multicolumn{7}{|l|}{ West } \\
\hline Interregional & 212 & 139 & 75 & 294 & 188 & 106 \\
\hline Black & 8 & 3 & 5 & 25 & 9 & 16 \\
\hline Intraregional & 132 & 127 & 5 & 195 & 187 & 8 \\
\hline Black & 5 & 4 & 1 & 7 & 4 & 3 \\
\hline \multicolumn{7}{|l|}{ Total } \\
\hline Interregional & 797 & 654 & 143 & 938 & 847 & 91 \\
\hline Black & 29 & 24 & 5 & 69 & 36 & 33 \\
\hline Intraregional & 563 & 468 & 95 & 717 & 627 & 90 \\
\hline Black & 26 & 14 & 12 & 40 & 41 & -1 \\
\hline
\end{tabular}

Source: U.S. Bureau of the Census $[1975 ; 1980 \mathrm{~b}]$.

pattern of concentration in the South and West. The aim of this section is to determine how interregional movement, by type of area of destination (i.e., central city, suburb, nonmetropolitan area), has influenced these rates of growth.

Table 4 shows annual average net flows, by region of residence (end of period) and by race for 1970-1975 and 1975-1979. Each flow is categorized by final areal type of destination. For example, the number -76 (thousand) for all migrants to central cities for the Northeast region means that on the average, from 1970 to 1975, there were 76 thousand more migrants from the Northeast (regardless of type of area of residence within that region) destined for central cities in other regions than there 
were migrants from other regions (regardless of type of area of residence within those regions) moving to central cities in the Northeast.

Migration to metropolitan areas is, as might be expected, directed on balance to the South and West; these regions received more migrants to their central cities and suburbs than they sent to the central cities and suburbs of the Northeast and North Central regions. In this transfer of population to metropolitan areas, the South had a net increase of 170 thousand persons per year from 1970 to 1975, and 110 thousand thereafter. The West gained from 150 (1970-75) to 260 thousand (1975-79) persons per year. On the other hand, the Northeast lost some 200 thousand persons per year, while average annual losses in the North Central states rose from 120 to 160 thousand.

The comparative attractiveness of central cities and suburbs in the South and West appears to have changed somewhat during the decade, especially in the South. During the first half of the decade, about three-fourths of Southern metropolitan net gains from interregional migration were sub-

\section{TABLE 4.}

Average Annual Net Flow, by Type of Area of Destination and by Region and Race: 1970-1979

(thousands of persons)

\begin{tabular}{lrrrr}
\hline Area of & \multicolumn{3}{c}{ North } & \\
Destination & Northeast & Central & South & West \\
\hline Central Cities & -76 & -34 & 44 & 67 \\
Total, 1970-75 & -122 & -74 & 88 & 107 \\
Total, 1975-79 & 6 & 5 & 23 & 12 \\
Black, 1970-75 & -14 & 11 & -11 & 14 \\
Black, 1975-79 & & & & \\
Suburbs & -120 & -90 & 129 & 80 \\
Total, 1970-75 & -100 & -84 & 24 & 160 \\
Total, 1975-79 & -4 & -3 & 0 & 7 \\
Black, 1970-75 & -13 & -7 & 0 & 20 \\
Black, 1975-79 & & & & \\
Nonmetropolitan & -71 & -115 & 192 & -6 \\
Total, 1970-75 & -54 & -70 & 156 & -33 \\
Total, 1975-79 & -14 & -13 & 26 & 1 \\
Black, 1970-75 & -6 & -4 & 14 & - \\
Black, 1975-79 & & & & \\
All Areas & -267 & -239 & 365 & 141 \\
Total, 1970-75 & -276 & -227 & 268 & 234 \\
Total, 1975-79 & -12 & -11 & 3 & 21 \\
Black, 1970-75 & -32 & 1 & 3 & 30 \\
Black, 1975-79 & -19 & & \\
\hline
\end{tabular}

Source: U.S. Bureau of the Census [1975; 1980b]. 
urban; in the West, suburban gains slightly exceeded those of central cities. From 1975 to 1979, however, metropolitan net gains in the South through interregional migration became concentrated in central cities, while the disparity between Western suburbs and central cities widened appreciably.

Perhaps the most striking feature of the data in table 4 , though, is the position of the South in terms of migration to nonmetropolitan areas. Throughout the decade and for both races, the South was the only region to receive more immigrants to its nonmetropolitan areas than it sent to nonmetropolitan areas in other regions. While to some extent this may be artifactual in that the South has the largest relative and absolute nonmetropolitan population [U.S. Bureau of the Census, 1980a] the magnitude of the flows shown in table 4 and the uniformity in direction of these flows suggests a real underlying phenomenon.

The interregional transfer of blacks to metropolitan areas is largely directed to the West, which was the only region to send fewer black migrants to metropolitan areas of other regions than it received throughout the decade. Again, the possibility of sampling error does not permit one to state this conclusion with real certainty. The transfer of black population to nonmetropolitan areas is directed, on balance, wholly to the South. In addition to the question of sampling error, the fact that nearly all of the nation's nonmetropolitan blacks reside in the South causes one to ask if any other outcome would have been possible.

\section{SUMMARY}

This paper has examined trends in interstate migration during the 1970 s for the four regions of the United States and, in particular, explored the relationship of this migration with nonmetropolitan expansion and the return to the city movement. The data show that the former trend is a very real one which has persisted throughout the decade and that population growth through interstate migration in nonmetropolitan America is, on balance, the result of nonblacks moving to the South from elsewhere in the nation. Except in the West, central cites continue to experience substantial losses of population through interstate migration. Interstate migration continues to be directed toward suburbs, and is especially vigorous in the West.

\section{FOOTNOTES}

${ }^{1}$ In both instances, the composition of metropolitan areas is that of 1970 . Interested readers should also note that the 1975-1979 data used here are taken from Tables 2 and 3 of U.S. Bureau of the Census, 1980b. Similar data are found in tables 39 and 42 , but care must be exercised in using the latter, since the row stubs titled "FROM BALANCE OF SMSA'S TO CENTRAL CITIES" and "BALANCE OF SMSA'S AT BOTH DATES" are reversed.

${ }^{2}$ Intrastate movement from 1975 to 1979 shows positive average annual flows, within all regions, ranging from about 4 thousand in the West to 133 thousand in the South [U.S. Bureau of the Census, 1980b, Table 39]. Adding these to the interstate flows for this period, shown in Table 1, yields total average annual net inflows to nonmetropolitan areas as follows: Northeast, 1 thousand; North Central, 30 thousand; South, 296 thousand; and, West, 51 thousand.

${ }^{3}$ Again, intrastate data by metropolitan/nonmetropolitan origin and destination are available only for 1975-1979. These show substantial net losses for central cities in each region and substantial net gains for suburbs in most regions. Combining intrastate data with the interstate data shown in Tables 2 and 3 shows, for central cities, average annual net outmigration of: Northeast, 295 thousand; North Central, 468 thousand; South, 444 thousand; West, 75 thousand. For suburbs, net annual inflows are: Northeast, 18 thousand; North Central, 211 thousand; South, 416 thousand; West, 258 thousand. 


\section{REFERENCES}

Beale, C. L. The Revival of Population Growth in Nonmetropolitan America. Economic Research Service Publication ERS-605. Washington: U.S. Department of Agriculture, 1975 .

Bowles, G. K. "Contributions of Recent MetroNonmetro Migrants to the Nonmetro Population and Labor Force," Agricultural Economics Research, 30:1522 (1978).

Cebula R. J. "Interstate Migration and the Tiebout Hypothesis: An Analysis According to Race, Sex and Age (1974)" Journal of the American Statistical Association, 69:876-879 (1974)

Farley, R. "The Changing Distribution of Negroes within Metropolitan Areas: The Emergence of Black Suburbs," American Journal of Sociology, 75:512-529 (1970).

Flynn, C. B. "General Versus Aged Interstate Migration, 1965-1970," Research on Aging, 2:165-176 (1980).

Frey, W. H. "Black Movement to the Suburbs: Potentials and Prospects for Metropolitan-wide Integration." Pp. 79-118 in F. D. Bean and W. P. Frisbie (eds), The Demography of Racial and Ethnic Groups. New York: Academic Press, 1978.

Fuguitt, G. V. and Zuiches, J. J. "Residential Preferences and Population Distribution," Demography, 12:491504 (1975)

Goodman, J. "People of the City," American Demographics, 2:14-17 (September, 1980.

Long, L. H. "Back to the Countryside and Back to the City in the Same Decade." Pp.61-76 in S. B. Laska and D. Spain (eds.), Back to the City: Issues in Neighborhood Renovation. Elmsford: Pergamon Press, 1980.

and Dahmann, D. C. The City-Suburban Income

Gap: Is it Being Narrowed by a Back-to-the-City Movement? Center for Demographic Studies Special Demographic Analysis 1. Washington: U.S. Bureau of the Census, 1980. and Hansen, K. A. Reasons for Interstate Migration: Jobs, Retirement, Climate, and Other Influences. Current Population Reports, Series P-23, No. 81. Washington: U.S. Government Printing Office, 1979. and Spain, D. Racial Succession in Individual Housing Units. Current Population Reports, Series P-23, No. 71. Washington: U.S. Government Printing Office, 1978 .

Nelson, K. P. "Black Suburbs and White Cities? Recent Trends in Intrametropolitan Migration," Paper presented at the annual meeting of the Population Association of America, Atlanta (1978).

Rives, N. W. and Serow, W. J. "Interstate Migration of the Elderly: Demographic Aspects," Research on Aging, 3:259-278 (1981).

Spain, D., Reid, J. and Long, L. Housing Successions among Blacks and Whites in Cities and Suburbs. Current Population Reports, Series P-23, No. 101. Washington: U.S. Government Printing Office, 1980.

Tucker, C. J. "Changing Patterns of Migration between Metropolitan and Nonmetropolitan Areas in the United States: Recent Evidence," Demography, 13:435-443 (1976).

U.S. Bureau of the Census. Mobility of the Population of the United States: March 1970 to March 1975. Current Population Reports, Series P-20, No. 285. Washington: U.S. Government Printing Office, 1975. . Estimates of the Population of Counties and Metropolitan Areas: July 1, 1977 and 1978. Current Population Reports, Series P-25, No. 873. Washington: U.S. Government Printing Office, 1980a.

Geographical Mobility: March 1975 to March 1979. Current Population Reports, Series P-20, No. 353. Washington: U.S. Government Printing Office, 1980b.

Wardwell, J. M. and Gilchrist, C. J. "Employment Deconcentration in the Nonmetropolitan Turnaround," Demography, 17:145-158 (1980). 